\title{
A TRAJETÓRIA DO VIOLEIRO TIÃO CARREIRO - DAS PRIMEIRAS DUPLAS AO SUCESSO DO CRIADOR E REI DO PAGODE
}

\section{THE CAREER OF THE VIOLEIRO (BRAZILIAN TEN STRING GUITAR PLAYER) TIÃO CARREIRO - FROM THE FIRST DUOS TO HIS SUCCESS AS THE CREATOR AND KING OF THE PAGODE GENRE}

\author{
João Paulo Amaral \\ Faculdade Cantareira \\ ipamaral21@gmail.com
}

\section{Resumo}

Esse trabalho traz um resumo da trajetória do cantor, compositor e violeiro Tião Carreiro (José Dias Nunes, 1934-1993). Por meio da análise musical de sua extensa discografia e da pesquisa de sua biografia desde o início da carreira até sua inserção e repercussão no segmento sertanejo nas décadas de cinquenta, sessenta, setenta e oitenta, procuramos entender em que medida o artista utilizou as matrizes, os gêneros e linguagens caipiras tradicionais, e de que forma os conciliou com outras tendências e gêneros relacionados aos interesses do mercado e da indústria fonográfica.

Palavras-chave: música popular; cultura popular; música caipira; música sertaneja; viola caipira.

I Conferência apresentada no dia 20 de outubro de 2016, dentro da programação do VII Encontro de Musicologia de Ribeirão Preto - A viola Caipira na Universidade: o regional, o local e o universal -, sob o título A obra musical do músico e compositor Tião Carreiro (José Dias Nunes, 1934-1993): os elementos constitutivos e as características de seu estilo. 


\begin{abstract}
This work presents a summary of the life and career of the singer, composer and viola caipira player Tião Carreiro (José Dias Nunes, 19341993). Through the musical analysis of his extensive discography and the research of his biography - from the start of his music career through his entry into and impact on the sertanejo scene in the fifties, sixties, seventies and eighties - we seek to understand how extensively the artist used the traditional caipira musical matrices, genres and languages, and how he reconciled these with other tendencies and genres related to the interests of the market and the phonographic industry.
\end{abstract}

Keywords: popular music; popular culture; Brazilian countryside music; Brazilian country music; Brazilian ten string guitar.

\title{
Lista de figuras
}

Figura 1: Capas dos LPs Rei do Gado (Continental, 1961) e Pagode na Praça (Continental, 1967). Fonte: http://www.recantocaipira. com.br/duplas/tiao_carreiro_pardinho/tiao_carreiro_pardinho.html (acesso em 17/12/2016).

José Dias Nunes (13/12/1934 - 15/10/1993), cantor, compositor e violeiro popularmente conhecido por Tião Carreiro, foi um dentre vários violeiros que chegaram a cidade de São Paulo e se inseriram no mercado fonográfico após deixarem zonas rurais das quais eram originários. Nascido num lugarejo na época chamado de Catuti², hoje Monte Azul, distrito de Montes Claros, norte de Minas Gerais, região de

\footnotetext{
2 Informações concedidas por Luiz Faria da Silva, amigo pessoal de Tião Carreiro desde 1968, mas que acompanhava a trajetória do artista desde o início de sua carreira. Luiz Faria também é violeiro e pesquisador do segmento sertanejo. Concedeu-nos uma entrevista no dia 15/10/2007 em São Paulo.
} 
grande diversidade de manifestações populares e matrizes caipiras ${ }^{3}$, Tião trabalhou como agricultor desde a infância quando, aos dez anos de idade, migrou para o interior do estado de São Paulo juntamente com sua família de lavradores em busca de melhores condições de vida. Pouco tempo depois, seu pai veio a falecer e the deixou a primeira viola.

Após trabalhar na roça em municípios paulistas como Paulópolis, Flórida Paulista e Valparaíso, no final dos anos quarenta e início dos cinquenta, Tião Carreiro formou suas primeiras duplas: "Zezinho e Lenço Verde", "Palmeirinha e Coqueirinho", "Palmeirinha e Tietêzinho" e "Zé Mineiro e Tietêzinho". Como muitos outros violeiros, cantava em circos na região de Araçatuba (SP) além de se apresentar em programas de rádio como "Assim canta o sertão", transmitido aos domingos pela rádio local de Valparaíso. Neste programa, o violeiro cantava serestas, sambas e músicas populares da época, sempre se acompanhando ao violão. "Depois que ele conheceu o circo, onde ele viu as duplas cantarem, tomou gosto pela música caipira. Então ele formou dupla com o Tietêzinho e tal", revelou o amigo pessoal de Tião Carreiro, violeiro e pesquisador Luiz Faria. Neste início de carreira, após ser advertido por um proprietário de circo que the disse ser necessário para a dupla que um dos dois tocasse viola, Tião Carreiro passou a se dedicar definitivamente ao instrumento. Segundo seu próprio relato ${ }^{4}$, nunca havia tido professor, tendo aprendido a tocar praticamente sozinho, inspirando-se nos toques de um dos importantes violeiros da época: Florêncio, da então famosa dupla de

3 Adotaremos neste trabalho a distinção entre música caipira e música sertaneja criada por Martins ( 1975). A primeira, de acordo com o autor, é sempre acompanhada de "algum ritual de religião, de trabalho ou de lazer"; e a segunda, ao ser apropriada pela indústria do disco no país, perde esse vínculo ao converter-se num produto, numa "mercadoria" (MARTINS, 1975, p. 105-113). Além disso, chamaremos de matrizes caipiras as estruturas, elementos, linguagens e características constitutivas dos gêneros musicais pertencentes aos antigos ritos e práticas lúdico-religiosas, portanto matrizes com as quais a música sertaneja manterá ligações de diversas formas no desenrolar de sua história. Para os conceitos como "gênero", "matrizes" e "estilo", utilizamos como referências os autores como Pascall (200 I), Fabbri (1985), Samsom (200 I) e Ulhôa (2003).

${ }^{4}$ Informações fornecidas pela família do artista, principalmente através de sua única filha Alex Marli Dias. 
Raul Torres e Florêncio5. Nesta época, em uma apresentação de Tonico e Tinoco num circo de Araçatuba, enquanto estes descansavam no hotel, Tião Carreiro decorou a afinação ${ }^{6}$ da viola deixada no circo por Tinoco, afinação esta que adotaria a partir de então: "Um dia num circo, fui ver um show de Tonico e Tinoco. Aí peguei a viola do Tinoco e decorei a afinação. Tinha eu 16 ou 17 anos" (Revista Moda e Viola, $n^{10} 14,1979$, p. 10, 11).

Esses dados nos mostram que provavelmente foi neste contexto dos circos, rádios e palcos das festas interioranas, que o violeiro começou sua formação musical na viola. Formado por diversas duplas e violeiros das zonas rurais onde provavelmente ainda ocorriam algumas manifestações e festas caipiras, este meio musical serviu de matrizes e referências para seus toques de viola. Essas influências e matrizes musicais caipiras podem ser facilmente identificadas em LPs como Sertão em Festa (1970) e Modas de viola classe A (1974), no qual o violeiro acompanha os sapateados de danças como a catira e o recortado. Além disso, ao participar de programas de rádio cantando canções populares da época (serestas e sambas) e ao mencionar o violeiro Florêncio como uma referência, Tião revela sua outra fonte de informações musicais: aquela representada pelo contato com os gêneros e músicas de massa difundidas pela indústria fonográfica por meio do disco e principalmente do rádio. Como veremos a seguir, essas duas tendências, uma mais tradicional e ligada as matrizes caipiras das zonas rurais, e outra mais de influência da indústria fonográfica e do

\footnotetext{
${ }^{5}$ Raul Torres e Florêncio foi uma das principais duplas do segmento sertanejo. Raul Montes Torres ( 1906-1970, Botucatu), que no início da carreira cantava solo utilizando às vezes o codinome de "Bico Doce", posteriormente formou dupla com seu sobrinho Serrinha e depois com Florêncio, tendo sido um compositor e intérprete de grande sucesso no rádio e em discos desde a década de trinta. Foi responsável por diversos clássicos sertanejos como "Cabocla Tereza", "A Moda da Mula Preta", "Saudades de Matão", entre outros, tendo sido parceiro do compositor João Pacífico nas conhecidas toadas históricas. Gravou desde gêneros mais caipiras como modas de viola, cateretês e cururus, até outros mais urbanos e de outras influências como sambas, batuques e principalmente emboladas. Florêncio (João Baptista Pinto, 1910 - 1970, Barretos), foi violeiro canhoto que, mesmo tendo realizado gravações desde a década de trinta ao lado de Raul Torres, somente em 1942 firmou a dupla com esse parceiro. Torres e Florêncio, juntamente com o sanfoneiro Rieli (Emílio Rielli Filho) fizeram o importante programa da Rádio Record "Os Três Batutas do Sertão" (FREIRE, 1996, p. 55-90; NEPOMUCENO, 1999, p. 34, 35).

6 Trata-se da afinação "Cebolão". Pesquisadores como Ivan Vilela mencionam que tal denominação é explicada por lendas e causos tradicionais que dizem que quando se tocava a viola com essa afinação, o som era tão bonito que fazia chorar as mulheres, como se estivessem descascando cebolas (VILELA PINTO, 2005, p.80).
} 
meio urbano, conviveram em toda a carreira do artista apresentandose de diferentes formas, combinações e intensidades de acordo com o período observado.

Em 1954, no circo "Rapa Rapa" na cidade de Pirajuí (SP), Tião Carreiro (que usava o nome de Zé Mineiro) conhece seu principal parceiro de carreira: Antônio Henrique de Lima, o Pardinho?', que cantava e tocava violão. Nesta época, os dois eram fãs de Zé Carreiro e Carreirinho, dupla em evidência no período?.

Algum tempo depois, o violeiro vem a conhecer o próprio Carreirinho, que então o convida para mudar-se para São Paulo em 1956. Neste mesmo ano, a convite do importante produtor e compositor Teddy Vieira, Tião Carreiro e Pardinho gravam seu primeiro disco de 78 rpm pela gravadora Columbia. $O$ disco continha na primeira face a moda de viola "Boiadeiro Punho de Aço", e na outra, o cururu "Cavaleiros de Bom Jesus", ambas de autoria de Teddy, que então batiza José Dias Nunes de Tião Carreiro ${ }^{10}$. Após gravarem mais um disco no ano seguinte, a dupla se separa. Tião então se une a Carreirinho e Pardinho a Zé Carreiro, ocorrendo uma troca entre as duplas. Tião e Carreirinho gravam dois discos em 1958 e três em 1959 enquanto Pardinho e Zé

7 Antônio Henrique de Lima, o Pardinho (São Carlos -SP 14/08/1932 - Sorocaba-SP O l/O6/200 1), foi o principal parceiro de Tião Carreiro. Tocava violão acompanhando os solos do violeiro e fazia a voz mais aguda no dueto, chamada pelos violeiros de primeira voz, apesar de ser, nesse caso, a segunda voz grave de Tião a que predominava como principal, sendo este um dos diferenciais importantes dessa dupla, influência presente em outras duplas e cantores até os dias atuais como Zé Mulato e Cassiano, Tião do Carro e Odilon e o romântico Daniel.

8 Em entrevista a Inezita Barroso no programa "Viola Minha Viola" da TV Cultura em homenagem a Tião Carreiro, exibido em 1999, Pardinho declarou que ele e Tião Carreiro, em meados da década de cinquenta, eram fãs da dupla Zé Carreiro e Carreirinho e que o repertório que cantavam no circo nesta época era basicamente compostos das suas canções.

9 Em 1954, Tião Carreiro se casa em Araçatuba com Nair Avanço Dias, e dois anos depois nasce a única filha do casal, Alex Marli Dias, que foi batizada pelo então amigo Carreirinho.

10 Segundo dados fornecidos pela família do violeiro, antes dos dois discos da Columbia, Tião registrou outros três discos. $\bigcirc$ primeiro disco de acetato, sem gravadora, no ano de 1952, contendo as músicas Viajando pra Matogrosso e Capital Variante, sem registro de autoria, intérprete, gênero, etc. O segundo e o terceiro, sem registro de data, foram uma gravação especial da "Casa Flávio Campana" localizada na Rua Domingo de Moraes, 2031, São Paulo(SP), na qual a dupla utilizava o nome de João Carreiro e Pardinho, interpretando um xote, duas modas de viola e um cururu, todos de autoria de João Carreiro e Teddy Vieira, revelando que o artista já tinha contato com o produtor. Para mais detalhes, vide discografia do artista em anexo. 
Carreiro gravam dois em 1958, três em 1959 e um em 1960.

Mas foi em 1960 que a carreira de Tião começa a deslanchar. Neste ano, ele volta a parceria com Pardinho gravando o disco que continha a canção rancheira "Borboleta do Asfalto" (Tião Carreiro), acompanhada de acordeom, violão, baixo acústico e trompete, e - sucesso "Alma de Boêmio" (Tião Carreiro/ Benedito Seviero), tango acompanhado de acordeom, baixo acústico e violão, sem viola. Este tango retratava o desgosto de um boêmio embriagado e vagabundo a lamentar a perda de sua amada, e incluía um diálogo do tipo radionovela entre a amada e o boêmio. Esta música impulsionou neste mesmo ano a considerável vendagem de cem mil discos, sendo regravada por outros artistas (NEPOMUCENO, 1999, p.34 I). Ainda neste ano, gravam "Pagode em Brasília" (Teddy Vieira/ Lourival dos Santos), música que representou o primeiro registro do gênero denominado pagode. A partir de matrizes como a catira, o recortado e moda-deviola, o pagode foi gênero que em síntese pode ser representado pela soma de uma interessante batida da viola com outra no violão (esta ultima chamada por alguns violeiros de cipó-preto), ritmo este que se tornaria a marca do artista que passou a ser considerado como "o criador e rei do pagode".

No final de 1961, Tião Carreiro e Pardinho lançam seu primeiro LP Rei do Gado contendo principalmente uma coletânea dos registros dos discos de 78rpm já gravados. Entre setembro de 1961 e meados de 1962, Tião voltaria a registrar três discos de 78rpm e seu segundo LP Meu Carro é Minha Viola ao lado de Carreirinho. Mas a partir de outubro de 1962, daria sequência às gravações e à parceria com Pardinho. Daí em diante, segundo depoimento de Luiz Faria, "(...) Tião seguiu com o Pardinho, desfazia a dupla, voltava, desfazia, voltava a dupla e assim viveram, aos trancos e barrancos, mas ficaram... numa somatória de quarenta anos de carreira, gravando e atuando".

A essa altura, o futuro empresário de shows de Tião Carreiro já trabalhava no segmento sertanejo paulista como "secretário" de um circo, nome dado aos produtores que contratavam as apresentações das duplas para tocar nos picadeiros. Mairiporãl' ', que seria produtor de Tião Carreiro entre 1968 a 1980, sobre o contexto das apresentações

11 Mairiporã (Roque de Moraes, 27/1//1947), que até hoje atua como empresário de duplas como Pedro Bento e Zé da Estrada, nos concedeu uma entrevista no dia 5/11/2007 em São Paulo. 
e a forma das contratações das duplas durante os anos sessenta até meados de setenta, revelou:

Na esquina do Paissandu com a São João, tinha um local que a gente chamava de "Café dos Artistas". E ali a gente encontrava todos os artistas famosos e os diretores de circo também. E ali era feita a contratação (...) Pouca gente tinha escritório. Zé Fortuna teve, primeiro Tonico e Tinoco, depois o Zé Fortuna. $\bigcirc$ resto, ninguém tinha escritório (...) Tião Carreiro e Pardinho nunca teve escritório (...) [E] era só circo. Era show e circo, acertava praticamente para o mês todo, dois meses. Fazia uma linha, por exemplo, daqui a Cuiabá e voltava em sequencia. (...) Entre cem circos, tinha cinco rodeios, o resto era tudo teatro, circo-teatro, a gente levara as peças.

"Café dos Artistas" era o mesmo estabelecimento conhecido como "Ponto Chic", localizado no largo do Paissandu (São Paulo), descrito por Caldas (1979, p.41-44) como ponto de encontro de artistas, duplas sertanejas, empresários, agentes de circos, proprietários de emissoras, entre outros, para o estabelecimento de contratações para apresentações ${ }^{12}$.

Após alguns anos não muito expressivos na Rádio Tupi, a partir do início dos anos sessenta, a dupla Tião Carreiro e Pardinho começa a firmar sua participação na Rádio Nacional de São Paulo (Rádio Clobo atualmente), experiência que duraria mais de oito anos em programas como o de Edgar de Souza e, posteriormente, de Oscar Martins e Carlos Alberto.

Ao mesmo tempo, a partir desses primeiros LPs, observa-se que gradativamente tanto Tião Carreiro e Pardinho quanto os outros letristas e compositores que forneciam repertório para os discos ${ }^{13}$ (ao

\footnotetext{
12 Waldenyr Caldas esclarece que "Em verdade, esse local é apenas a continuação de uma série de outros três, onde esses profissionais sempre se reuniam. $\bigcirc$ primeiro local foi a Avenida lpiranga esquina com a Avenida São João, no tradicional Bar do Jeca (nome dado justamente por causa dessas reuniões). Posteriormente, esse local foi substituído por um outro bar na Avenida São João esquina com a rua Dom José de Barros." (CALDAS, 1999, p.4 1)

13 Ao lado de Tião Carreiro, os principais compositores e parceiros eram: Lourival dos Santos, Teddy Vieira, Moacyr dos Santos, Dino Franco, Zé Carreiro, Zé Fortuna, Carreirinho, dentre outros.
} 
que tudo indica, normalmente Tião não era responsável pelas letras de suas composições, mas sim pelas melodias ${ }^{14}$ ), vão em certa medida, orientando-se por fórmulas e padrões que obtinham sucesso nas rádios e na venda de discos ${ }^{15}$. Além disso, de maneira geral, observa-se que os discos da dupla vão sempre contemplar tanto gêneros de massa ligados à indústria fonográfica (tangos, milongas, rancheiras, guarânias, rasqueados, polcas paraguaias, sambas, toadas, baladas etc.) quanto gêneros mais caipiras (modas de viola, cururus, cateretês, pagodes, arrasta-pés). As palavras de Luiz Faria confirmam essa constatação sobre as duas tendências: "O Tião, em todos LPs que ele gravava, ele fazia questão de ser meio a meio, metade pagode [referindo-se aos gêneros mais caipiras], metade romântico". No entanto, observamos que na discografia do artista os gêneros caipiras predominam em relação aos de massa.

A convivência entre as duas tendências também pode ser observada nas capas dos LPs da década de sessenta por exemplo, quando ocorre alternância entre essas temáticas, indo desde fotos da dupla vestida como boiadeiros gaúchos ou com ilustrações de bois em cenas rurais (LPs Rei do Gado, Casinha da Serra, Meu Carro é minha Viola, Linha de Frente, Boi Soberano), até fotos mais urbanas da dupla vestida em roupas mais sociais (Pagode na Praça e Em tempo de avanço) ${ }^{16}$.

\footnotetext{
14 Segundo Luiz Faria, Mairiporã e outros pesquisadores e violeiros, normalmente Tião não compunha letras, e sim musicava ou ajudava a musicar as letras de seus parceiros compositores. Relatam, ainda, que era comum no segmento sertanejo os autores presentearem amigos e conhecidos com parcerias nos registros de suas músicas, mesmo sem estes terem de fato participado da criação das composições. Observando a discografia da dupla, Pardinho não teve grande participação como compositor, não chegando a ser responsável por duas dezenas de composições dentro do extenso repertório gravadas pelos artistas, o que não significa que ele não compusesse de uma maneira geral.

15 Em linhas gerais, esse comportamento é identificado no segmento sertanejo: "a música não é necessariamente produzida com fins comerciais, mas é fora de dúvida que os compositores desse gênero procuram descobrir qual o padrão que está interessando às gravadoras e emissoras no momento para se orientarem por ele" (MARTINS, 1975, p.4 I).

16 Sobre as vestimentas nas capas, Luiz Faria observou que inicialmente as primeiras duplas caipiras utilizavam o padrão da época de Cornélio Pires: camisa xadrez, lenço no pescoço e chapéu de palha. Aos poucos, as duplas foram adotando e inventando modas ao usar roupas mais extravagantes e exóticas como as de boiadeiros gaúchos, mariachis mexicanos etc., sempre buscando inovar e chamar a atenção. Ele acrescenta que no caso de Tião Carreiro e Pardinho, após aderirem a essas modas, com o passar dos anos o vestuário foi sendo trocado por roupas mais comuns, como terno e camisas.
} 

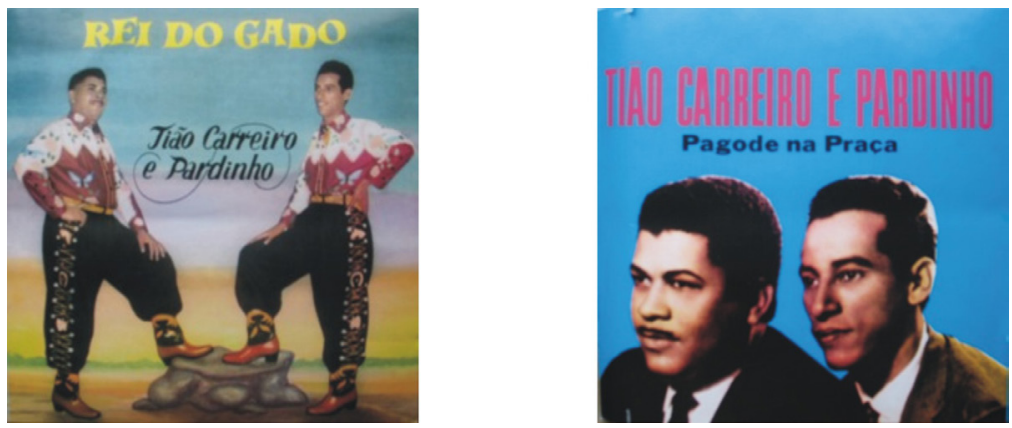

Figura 1: LPs Rei do Gado (Continental, 1961) e Pagode na Praça (Continental, 1967).

Fonte: http://www.recantocaipira.com.br/duplas/tiao_carreiro_pardinho/tiao_carreiro_ pardinho.html (acesso em 17/12/2016).

Até os LPs de meados da década de sessenta, a separação entre essas duas tendências é bem visivel. As instrumentações diferenciadas ${ }^{17}$ além da viola e o violão e os arranjos e temáticas mais urbanas e "românticas" eram reservados aos gêneros mais de massa. Os acompanhamentos mais simples como viola e violão e os temas mais rurais eram por sua vez aplicados nos gêneros mais caipiras.

A partir do final da década de sessenta, observamos que a distinção entre as duas vertentes vai ficando gradativamente menos acentuada, na medida em que gêneros mais urbanos e de massa, como o tango e a canção rancheira, vão sendo abandonados, dando lugar a outros mais híbridos, como valseados, sambas caipiras e principalmente balanços. Este gênero, semelhante ao batuque e ao samba caipira, foi largamente utilizado principalmente a partir do sucesso de "Rio de Lágrimas" (Tião Carreiro/ Piraci/ Lourival dos Santos) lançada em 1970 no LP A Força do Perdão. Nesses gêneros mais híbridos, ocorre a alternância entre temáticas rurais e urbanas, às vezes com presença de romantismo. No entanto, figuram de maneira muito presente os gêneros mais tradicionais como os pagodes, cururus, cateretês e modas de viola, característica que resulta no convite para a dupla participar do filme "Sertão em Festa" em 1970'8 É também a partir do final dos anos

\footnotetext{
17 Em muitos dos LPs desta época, quando havia outros instrumentos além da viola e o violão nos acompanhamentos, em suas contracapas vinha a indicação: "com acompanhamento".

18 No filme de Oswaldo de Oliveira, a convite do grande produtor, radialista e compositor de música caipira, o Capitão Furtado (Ariovaldo Pires, sobrinho do pioneiro Cornélio Pires), Tião Carreiro e Pardinho encenam o papel da própria dupla, obtendo grande sucesso de bilheteria ao lotar por 32 semanas o cinema Art Palácio, no Largo do Paissandu em São Paulo. (NEPOMUCENO 1999, p.344).
} 
sessenta, que ocorre gradativa aplicação de arranjos, mesmo que ainda simples, nas introduções e acompanhamentos com viola, violões, cavaquinhos, acordeons, percussão, baixo e às vezes órgão, guitarra havaiana, banjo etc. Usa-se da abertura de melodias em terças geralmente entre violões, acordeons, tanto nas introduções como nas "costuras 19", mantendo-se todavia características e linguagens ainda dentro do universo dos gêneros mais tradicionais. Sobre esses arranjos de antigamente, Mairiporã comenta que como não havia maestro ou arranjador, eram feitos na hora de gravar, quando o artista dava a "intenção" e os músicos "de ouvido" procuravam dar forma àquela ideia musical sugerida:

Hoje o maestro faz os arranjos e a base, chega lá tá tudo pronto, antigamente era na orelhada tudo ali. $\bigcirc$ artista dava a intenção pro, pro ... mas não tinha nem maestro, dava intenção para os músicos...(...) $\bigcirc$ artista chegava 'larari laralara, eu quero o arranjo assim' e o cara fazia. Era tudo de orelhada. ${ }^{20}$

Sobre a escolha de repertório e eventuais palpites e sugestões estéticas sobre os arranjos no momento das gravações, Mairiporã e Luiza Faria afirmam que Tião tinha pleno controle e autonomia em relação à sua gravadora, a Chantecler-Continental. Além disso, Mairiporã acrescenta que o violeiro centralizava as decisões: "Repertório do Tião quem mandava era ele, e acabou".

Em 1971, aparece o primeiro disco do artista que traz o recurso tecnológico do estéreo, fato que permitiu ampliar ainda mais alguns recursos de arranjo como as dobras praticadas nos estúdios na medida em que estas funcionavam melhor por serem ouvidas separadamente em dois alto-falantes. A essa altura, Pardinho já não gravava mais violão, já que, com os recursos da gravação multicanal nas fitas magnéticas, não era mais necessário que se gravassem as vozes e os instrumentos ao mesmo tempo, como era feito principalmente nos tempos do disco de 78 rpm. Ao contrário disso, os músicos de estúdio podiam gravar separadamente as bases para depois serem

\footnotetext{
19 Maneira popular de se referir aos contracantos e melodias criados para comentar e ornamentar ("florear") os versos cantados e os espaços entre estes.

20 Comentário presente na entrevista que nos concedeu em 5/1 1/2007.
} 
colocadas as vozes²! Nesta fase, além de Tião Carreiro, nota-se a presença de outra viola a participar das gravações e arranjos, tocando não só nas introduções, como também ornamentando de maneira livre durante os versos cantados, e que segundo apuramos provavelmente seria do violeiro e violonista Bambico22. Vale lembrar que, até 1982, os LPs de Tião Carreiro não continham ficha técnica com nome dos músicos participantes. Bambico veio do interior para São Paulo provavelmente por volta de 1965/66 e já no início da década de setenta figurava como um dos principais músicos e arranjadores do segmento nos estúdios da capital. Segundo Luiz Faria, por pelo menos dez anos Bambico atuou em gravações e algumas apresentações ao lado de Tião gravando inclusive viola caipira nas introduções das canções do artista:

\section{(...) durante uns dez anos, no mínimo, todas as introduções de viola, na gravação, quem fazia era o Bambico(...) $\bigcirc$ Bambico era assim: o Tião demorava um dia, dois pra criar, aí criava, chamava o Bambico, fazia uma vez, ele falava 'faz de novo', ele vazia a segunda vez, pronto, já ia gravar. Ele pegava na hora, era bom de cabeça. 23}

Mesmo que Bambico não tenha gravado todas as introduções de viola de Tião Carreiro durante os dez anos mencionados por Luiz Faria, não se pode negar sua importante participação e contribuição nas gravações do artista, revelada tanto nas palavras de Luiz Faria e Mairiporã, como na de outros pesquisadores e violeiros. Esta participação nos leva à hipótese do próprio Bambico, no ambiente das gravações, ter colaborado em certa medida na criação de alguns arranjos e introduções de viola dos LPs de Tião Carreiro nos quais

21 Segundo os relatos de Mairiporã e Luiz Faria, Pardinho gravava violão mais no tempo dos discos 78rpm, época em que se gravava em apenas um canal e, por vezes, com todos tocando e cantando em apenas um microfone. Com o advento nos estúdios da gravação multicanal com os gravadores de rolo de fita magnética, as bases, incluindo os violões, passaram a ser gravadas por músicos de estúdio como Bambico, Itapuá, Tupi, Zino Brito e às vezes pelo próprio Tião Carreiro.

22 Domingos Miguel dos Santos (1944-1982), natural de Umuarama (PR), foi multiinstrumentista e músico de destaque ao atuar nos estúdios do segmento sertanejo também como arranjador e criador de introduções de viola nas gravações de artistas como Tião Carreiro, Jacó e Jacozinho, Rolando Boldrin, dentre outros. Gravou LPs como intérprete nas duplas que formou com Bambuê e João Mulato. Lançou o LP de solos de viola "Brincando com a viola" (Chantecler/1982). Segundo Mairiporã e Luiz Faria, Bambico chegou em São Paulo entre 1965 e 1966.

23 Entrevista concedida em 15/10/2007, São Paulo. 
participou.

No início dos anos setenta, a dupla Tião Carreiro e Pardinho já atraía plateias numerosas em apresentações, chegando no ano de 1972 a receber "sete, oito mil pessoas em estádios, cinemas e circos, altíssimos números para a época” (NEPOMUCENO, 1999, p.344). A partir de 1973, a cada ano a dupla lançava no mínimo dois LPs, chegando a cinco discos em 1979, alguns como coletâneas de sucessos, pagodes, modas de viola e uma de tangos. Mairiporã lembra que os LPs Hoje eu não posso ir (1970) e Rio de Pranto (1976) obtiveram altas vendagens. Quando indagado se um LP desses chegava à marca de quinhentas mil cópias, revelou:

\begin{abstract}
$\bigcirc$ Tião vendia muito mais. $\bigcirc$ Tião com $\bigcirc$ Teixeirinha ${ }^{24}$ vendeu na época, mais ou menos uns .... cinco milhões de LPs, nas primeiras tiragens. (...) Pra você ter uma ideia, ficava aquelas carretas do fim de semana, aquelas carretas pra levar disco pro interior, dez, quinze esperando fabricar o disco já pra levar. Tião Carreiro e o Teixeirinha, os dois venderam muito disco, nossa! ${ }^{25}$
\end{abstract}

Esses fatos têm correspondência direta com o período de racionalização e crescimento da indústria fonográfica nos anos setenta. Esse crescimento ocorre não só no mercado sertanejo, que além da Chantecler ${ }^{26}$ passa aos poucos a contar com outras grandes gravadoras, como em todo o mercado fonográfico brasileiro que, de 1968 e 1976, registra crescimento superior a 40\%, atingindo a quinta posição no mercado mundial de 1978 para 1979 (VICENTE, 200 I, p.53; DIAS, 2000, p.54, 55)27. Concomitantemente, ocorre uma maior abertura

24 O cantor gaúcho Victor Mateus Teixeira (1972-1985), o Teixeirinha, natural de Rolante (RS), ficou muito conhecido pelo sucesso de sua autoria "Coração de Luto", gravado em 1960 pelo selo Sertanejo, canção que acabou sendo tema em 1966 do primeiro de alguns longas-metragens encenados pelo artista. (Dicionário Cravo Albin de Música Brasileira, consultado no site www.dicionariompb.com.br em dezembro de 2007)

25 Entrevista concedida em 5/11/2007, São Paulo.

26 A Chantecler foi criada em 1958 pela empresa Cássio Muniz, que representava os produtos RCA-Victor, General Motors e os aviöes Cessna. (NEPOMUCENO 1999, p. 1 43)

27 Em Muller (2005) também encontramos dados da Associação Brasileira dos Produtores de Disco que mostram que, em 1968, foram vendidas pouco menos de 15 milhöes de unidades, entre compactos simples, duplos e LPs e em 1979 este número havia saltado para 64 milhöes: um crescimento, em apenas uma década, de mais de $400 \%$, na qual o ano de 78 apresenta o recorde de vendas que gerou certa abertura para lançamentos de música apenas instrumental. (MULLER, 2005, p. 19,64) 
também para o segmento da música instrumental brasileira, verificado a partir do ressurgimento do choro com seus festivais televisivos, do surgimento de expoentes da música instrumental como Egberto Gismonti e Hermeto Pascoal, da proliferação de selos independentes que principalmente a partir de 1980 passam a registrar música instrumental e da realização de importantes festivais de jazz nacionais, dentre outros (MULLER, 2005, p.47-70).

Nessa época, uma possivel demanda por um segmento sertanejo instrumental, mesmo que pequena, pode ter proporcionado brechas para o registro de discos instrumentais de viola ${ }^{28}$. Tião Carreiro, certamente seria uma boa opção para sua gravadora ChanteclerContinental, visto que possuía tanto uma carreira de sucesso a essa

28 Acerca do segmento instrumental sertanejo, poderíamos grosso modo dividi-lo em duas vertentes: uma vertente erudita e uma popular. A vertente erudita, agrupa os trabalhos onde ocorre o que se pode chamar de "apropriação culta" das matrizes caipiras (ZAN, 2003, p.7; 2004, p.9), unindo em suas obras os universos da música caipira às esferas da música erudita, da música popular brasileira e instrumental brasileira ou do jazz, cada qual, obviamente, de maneiras, intensidades e com influências diferentes. Nessa linha identifica-se nomes como Theodoro Nogueira, que compôs "Concertino para Viola e Orquestra de Câmera" e os "Prelúdios nos modos da viola brasileira" gravados pelo violonista Antônio Carlos Barbosa Lima em 1963 no LP Viola Brasileira (Chantecler); Geraldo Ribeiro, também aluno de Theodoro, que registraria em LP uma transcrição de Theodoro intitulada "Bach Na Viola Brasileira"(Chantecler, 1972); e posteriormente nomes como Renato Andrade, Heraldo do Monte, Tavinho Moura, Almir Sater, Roberto Corrêa, Paulo Freire, Ivan Vilela, Fernando Deghi, dentre outros. A vertente popular agrupa trabalhos de artistas mais tradicionais, desprovidos de formação musical formal, identificada na obra principalmente de violeiros que, de uma maneira ou de outra, representam as matrizes musicais tradicionais caipiras, em maior ou menor grau de transformação. Nomes como o do violeiro Arlindo Santana insere-se nessa vertente, e seu "Paixão de Caboclo repicado" foi o registro mais antigo por nos localizado de viola instrumental - apesar de sem data, era disco de 78rpm provavelmente do início de 1930, já que era um dos violeiros trazidos pelo pioneiro Cornélio Pires para suas gravações nessa época. Embora alguns não chegaram a registrar discos instrumentais, apenas de canção, identificamse nessa vertente violeiros de destaque como Laureano (1909-1996), Florêncio (19101970), Zé Pagão (1912-?), Laurípio Pedroso (? - 1965), entre outros. Mais tarde, aparecem violeiros como Julião Saturno que lança um compacto dulplo instrumental "Julião e sua viola eletrônica" (California, 1960), Zé do Rancho, com o LP "A Viola do Zé" (RCA, 1966) e Tião Carreiro com "É isso que o povo quer - Tião Carreiro em solos de viola caipira" (Chantecler-Continental, 1976) e "Tião Carreiro em solo de viola caipira (Continental, 1979). Além desses, alinham-se nesta vertente popular outros inúmeros violeiros como Bambico, Téo Azevedo, Cedeão da Viola, Zé Coco do Riachão, Helena Meireles, dentre outros que mais tarde viriam lançar discos inteiramente instrumentais. 
altura consolidada ${ }^{29}$, o que the dava respaldo e crédito perante a gravadora e ao mercado, quanto todo prestígio e bagagem musical como violeiro solista necessários para realizar tal projeto instrumental de maneira bem sucedida. $\bigcirc$ que acabou ocorrendo com o registro de dois LPs inteiramente instrumentais em 1976 com "É isso que o povo quer - Tião Carreiro em solos de viola caipira" (Chantecler-Continental) e 1979 com "Tião Carreiro em solo de viola caipira (Continental). Nesses discos, além de cururus, toadas, guarânias, polcas, corridos, sambas caipiras, balanços e outros gêneros que permearam toda a carreira do violeiro, também aparecem em significativa quantidade pot-pourris de pagodes (7 das 28 faixas totalizadas nos dois discos) com a denominação "seleção de pagodes", nas quais mistura as melodias, solos e introduções de vários pagodes gravados anteriormente pelo violeiro. Nestas seleções, Tião Carreiro evidencia sua habilidade e destreza nos solos e acompanhamentos, imprimindo a técnica e musicalidade marcantes de seu estilo como instrumentista de viola. Em ambos os discos, acompanhado basicamente de violões e percussão, o violeiro explora a viola caipira desde a maneira mais tradicional, quando utiliza simples melodias nas tradicionais escalas duetadas, até em melodias rítmica e melodicamente mais complexas, muitas vezes de execução tecnicamente difícil. Dono de uma "pegada" pesada no instrumento, utiliza-se, dentre outras técnicas, da alternância entre o polegar e o indicador da mão direita para solar melodias, arpejos, ornamentos, ligados, pizzicatos, staccatos, notas percussivas, expressivos vibratos, notas pedais, notas produzidas em cordas soltas, entre outros ${ }^{30}$.

Ainda na década de 1970, ocorre também o crescimento de programas de rádio e televisão especializados no segmento sertanejo. (MARTINS, 1975, p.38-44; CALDAS, 1979, p.26). É justamente na década de setenta que Tião Carreiro e Pardinho participam do mais importante programa radiofônico do segmento, o "Linha Sertaneja Classe A" da Rádio Record, programa iniciado por volta de 1973 com apresentação Zé Russo e posteriormente de Zé Bettio. Este programa

29 Waldenyr Caldas observa que em 1979, junto com Léo Canhoto e Robertinho e Tonico e Tinoco, Tião Carreiro e Pardinho eram as duplas "medalhões da música sertaneja", tendo escritório e empresários próprios, ao contrário da maioria das outras duplas que eram obrigadas a frequentar os pontos de encontro de empresários à procura de shows (geralmente com propostas exploradoras), como o "Ponto Chic" no Largo do Paissandu (CALDAS, 1979, p.41,42).

30 Para mais detalhes sobre as técnicas e elementos utilizados pelo violeiro consultar AMARAL PINTO (2008). 
duraria até início dos anos oitenta, sendo transmitido todas as noites em horário nobre, no qual Tião Carreiro e Pardinho era uma das duplas privilegiadas, dispondo de meia-hora exclusiva todas as sextas-feiras. ${ }^{31}$ (CALDAS 1979, p. 19, 32).

Após algumas tentativas frustradas da indústria fonográfica na conquista do público de classe média ${ }^{32}$ para o segmento sertanejo, é no início da década de setenta que aparece a dupla de sucesso Léo Canhoto e Robertinho, a primeira entre outras que passam a utilizar gêneros e instrumentações remanescentes da jovem guarda. Ritmos como baladas e rocks figuram ao lado de bateria e instrumentos eletrônicos como guitarras, teclados, contrabaixos. As vestimentas imitam a estética dos cowboys dos filmes de bang-bang ítalo-americanos e as temáticas das músicas passam a ser mais urbanas. Alinham-se nesta tendência o cantor-solo Sérgio Reis e posteriormente duplas como Milionário e José Rico. Estes artistas representam os primeiros passos da indústria fonográfica rumo ao seguimento "romântico" da música sertaneja de massa que iria se consolidar nas décadas de oitenta e noventa. (CALDAS, 1979, p.53-61; ZAN, 1995, p.4-6).

No entanto, no início dos anos setenta, duplas mais antigas como Tonico e Tinoco, não aceitaram sugestões como a da própria gravadora Chantecler-Continental de incluir guitarras e outros acompanhamentos modernos em seus discos, na tentativa de recuperar vendagens que a mais de dez anos não eram satisfatórias. (NEPOMUCENO, 1999, p.308,309).

Já Tião Carreiro absorve alguns traços destas tendências de mercado. Notamos na discografia deste período a presença de algumas

31 Informações obtidas também nas entrevistas com Luiz Faria e Mairiporã, realizadas em 15/10/2007 e 5/11/2007 respectivamente. Segundo Mairiporã, o programa "Linha Sertaneja Classe A" tinha "audiencia total. Podia passar em qualquer casa do interior principalmente, que tava tocando. Depois veio a novela (...) Isso era até oitenta [1980] (...) Era sagrado, chegava ali o cara tava no rádio".

32 Foram realizadas algumas iniciativas como o Festival de Viola da TV Tupi (1970), articulado pelo maestro Júlio Medaglia e o movimento "Nhô Look" encabeçado pelo maestro Rogério Duprat e financiado pela companhia Rhodia, que tentava lançar uma moda country no país. Promovendo refinamento na linguagem, modernização nos arranjos e certa limpeza das rusticidades próprias da música sertaneja, tais ações buscaram, sem sucesso, atingir públicos de classe média e jovens - tendências internacionais segundo Vicenti (200l, p.86) - no contexto de decadência do movimento da Jovem Guarda (MARTINS 1975, p.44,45; CALDAS, 1979, p.46-53;ZAN, 1995, p.4). 
baladas, guarânias, balanços e cateretês com temáticas românticas e urbanas no repertório; capas de LPs em que aparece com vestimentas de bang-bang e chapéus de comboy colorido, dentre outros. No entanto, observamos que suas características gerais eram predominantemente ligadas ao segmento que, no final da década passou a ser denominado como sertanejo de raiz em contraposição ao romântico. Isso porque seus discos eram notadamente marcados pela presença dos gêneros e linguagens mais caipiras, pela viola evidenciada principalmente em seus pagodes e pelas características mais tradicionais predominantes nos arranjos. Isso revela que, de certa forma, Tião Carreiro conseguia conciliar os prováveis interesses da gravadora em modernizar o repertório, mantendo presentes, ao mesmo tempo, os gêneros caipiras. Além disso, o sucesso quase que permanente na vendagem de seus discos desde a década de sessenta provavelmente the garantia uma posição mais confortável frente a eventuais imposições da gravadora. Essa condição explicaria, portanto, a postura e poder de decisão que o violeiro tinha frente ao repertório e a instrumentação, segundo observamos acima nos relatos de Mairiporã e Luiz Faria.

Em 1978, devido a desentendimentos, a dupla Tião Carreiro e Pardinho se separa, retornando no ano de 1981. Neste período, Tião forma dupla com Paraíso (José Plinio Transfereti33) enquanto Pardinho une-se a Pardal ${ }^{34}$. Com Paraíso, Tião lança quatro LPs além das coletâneas de gravações anteriores ao lado de Pardinho. A partir do primeiro LP da nova dupla, intitulado Viola Divina (1978), podemos notar uma maior organização e profissionalização na produção dos discos, que passaram a incluir ficha técnica mais minuciosa detalhando itens como: capa, direção de arte, fotos, administração de repertório, além de direção artística, técnico de som, mixagem estúdio, etc. Neste álbum pela primeira vez é utilizado racionalmente o verso da capa para inserção de fotos dos artistas. Segundo o pesquisador Waldenyr Caldas, nesta época, Tião Carreiro, ao lado de artistas como Tonico e Tinoco e Léo Canhoto e Robertinho, eram considerados "medalhões

33 Nascido em 01/06/1947, na cidade de Elias Fausto (SP), antes de usar o nome de Paraíso, José Plínio Transfereti formou outras duplas com nome de Smith, como Scott e Smith, que na década de setenta seguiu a linha sertaneja "moderna" iniciada por Léo Canhoto e Robertinho. (CALDAS 1979, p.53). Com Paraíso, Tião Carreiro gravou quatro LPs pela Chantecler, que a partir de 1980 foi incorporada gravadora Warner. Atualmente Paraíso forma dupla com Mococa.

34 A dupla Pardinho e Pardal gravou cinco LPs entre 1978 e 1981, pela Chantecler/ Warner. 
da música sertaneja" devido à sua grande popularidade, não sendo necessário frequentar locais como o "Ponto Chic"35 (CALDAS, 1979:4144). Sobre os roteiros de apresentações e os cachês de duplas como Tião Carreiro e Pardinho ainda em 1977, o jornalista Aramis Millarch revelou:

Pois Tônico \& Tinoco (com mais de 30 anos de carreira), Tião Carreiro e Padrinho, Pedro Bento e Zé da Estrada, são artistas caros, com cachês fixos e que cumprem extensos roteiros de apresentações, principalmente no interior de São Paulo, Minas Gerais, Mato Grosso, Coiás e Santa Catarina (...). Pois, o mercado de música sertaneja é amplo, prova nas dezenas de lançamentos mensais feito por 12 gravadoras que disputam o setor, algumas trabalhando apenas com este tipo de produção. ("Caipiras com Marketing", Aramis Millarch, publicado no Estado do Paraná 14/05/1977)

No entanto, no início da década de oitenta observa-se uma crise na indústria fonográfica brasileira que reflete na diminuição do ritmo de lançamentos do artista que a partir deste período, raramente ultrapassa a marca de um LP por ano. Ao mesmo tempo, observamos nos discos deste período algumas tentativas mais diretas em direção à adoção do romantismo nas temáticas. No entanto, a presença de gêneros ligados às matrizes caipiras ainda se mantém no repertório. Nesta época, gradativamente a música sertaneja começa a adentrar com maior penetração na mídia televisiva, chegando aos poucos às rádios FM, além de sofisticar seu circuito de exibição que, dos circos e espaços periféricos, passa aos rodeios itinerantes, às feiras e exposições agropecuárias, cada vez mais com ares de superprodução ${ }^{36}$ (VICENTI,

35 Localizado no Largo do Paissandu em São Paulo, o "Ponto Chic" ou "Café dos Artistas", segundo Caldas, era um conhecido bar em que ocorria uma certa desigualdade entre a grande oferta de duplas sertanejas e a procura insuficiente por parte dos empresários, proprietários de circo, de emissoras, de salöes, etc., o que gerava pagamentos e contrataçöes exploratórias dos artistas. Assim, o autor acrescenta que era quase que "humilhante" para duplas mais populares e bem sucedidas frequentar tal mercado de negócios (CALDAS, 1979, p.41-44).

36 Vicenti menciona o sucesso da série televisiva "Carga Pesada" que contava com trilha sonora de artistas sertanejos como Leo Canhoto e Robertinho, Sérgio Reis e Renato Teixeira, os rodeios de Beto Carreiro, além da apresentação "A Grande Noite da Viola" em 12/06/198 I que reuniu no Maracanázinho as "grandes estrelas do segmento" como o próprio Tião Carreiro e Pardinho, Milionário e José Rico, Tonico e Tinoco, e Cascatinha e Inhana, com cobertura da TVS e realização da Chantecler e Rádio Nacional do Rio de Janeiro (VICENTI, 200 I, p. 108 e nota de rodapé). 
2001 , p. 107, 108). Em 1983, já novamente ao lado de Pardinho, Tião grava o LP No Som da Viola que traz a presença marcante do arranjador José Barbosa dos Santos (Marinho) empregando largamente arranjos para violinos, utilização de uma espécie de teclado chamado de piano Elka, guitarra havaiana, baixo elétrico, cavaquinho, violões e viola, disco no qual predominam os temas mais românticos.

Abalada pela crise econômica nacional, a década de oitenta seria de "grande turbulência" para a indústria fonográfica (VICENTI, 2001, p.87) o que refletiu nos poucos lançamentos ${ }^{37}$ do violeiro que procuravam ora satisfazer o público de música sertaneja de raiz com LPs como Modas de Viola Classe A - vol.4 (1984), ora tentando novas soluções pouco eficazes para atingir o crescente público do sertanejo romântico que começa a ser alvo de grandes gravadoras multinacionais. Desta forma, busca "modernizar" a estética dos seus discos na tentativa de acompanhar o crescente sucesso das novas duplas sertanejas e românticas como Chitãozinho e Xororó, Zezé di Camargo e Luciano, Leandro e Leonardo, entre outras. Até nos gêneros caipiras mais tradicionais como o cururu, gradativamente os arranjadores e músicos dos seus discos tentam aplicar instrumentações como violinos, teclados, saxofones, guitarras, coro e bateria, resultando em arranjos estilizados e rebuscados. E a viola caipira, quando aparece, não é necessariamente tocada pelo artista. $\bigcirc$ último disco do violeiro, após mais uma separação com Pardinho, foi $\bigcirc$ Fogo e a Brasa gravado em 1992 ao lado de Praiano. Esse disco representa, sem sombra de dúvida, - auge desta estilização na carreira do violeiro, momento em que já está consolidado o segmento sertanejo pop romântico nos padrões da indústria fonográfica internacional. Em 15 de agosto de 1993, Tião Carreiro veio a falecer em São Paulo devido a complicações provenientes de diabetes. Pardinho viria a falecer apenas em 200 I, na cidade de Sorocaba.

Esse período iniciado nos anos noventa, segundo Alem (20042005), corresponde ao processo de consolidação de um novo modelo da ruralidade brasileira, fenômeno que abrange denominações ambíguas como country (termo que evoca a modernidade dos padrões

37 Em Dias (2000, p. 77) a autora aponta que "na década de 80, os números do mercado fonográfico retratam a inconstância e a incerteza da vida econômica nacional. Desde 1979, quando o país chegou a ocupar a quinta posição no mercado mundial, os números passam a ser decrescentes, até 1986, quando se recupera, mesmo de maneira inconstante". 
norte-americanos), e caipira e sertanejo (representantes das tradições da antiga sociedade agrária). $\bigcirc$ autor afirma que a expansão dos rodeios, shows de duplas sertanejas, exposições agropecuárias, rituais cívicos e outros eventos ruralistas aliados ao apoio das prefeituras locais, da mídia televisiva, radiofônica, impressa e eletrônica, da indústria fonográfica, grifes do vestuário country, empresas publicitárias, produtores, profissionais especializados e patrocinadores passou a atrair públicos massivos e consumidores de símbolos ruralistas tanto no espaço rural como no urbano ${ }^{38}$.

Dessa forma, a ruralidade brasileira atual não emerge nem se situa mais unicamente no campo. A categoria rural tomou uma dimensão geográfica, social e simbólica imprecisa, até se tornar quase indefinida, graças ao caráter diluído e abrangente que tantos rituais, produtos e símbolos the conferem (ALEM, 2004-2005, p.96).

No entanto, principalmente a partir do final dos anos noventa, frente à forte massificação atingida pelo segmento sertanejo moderno, pop ou romântico, e diante deste novo contexto da ruralidade brasileira "caipira sertaneja country" apontado por Alem, ocorre um relativo crescimento na demanda pelo segmento sertanejo de "raiz" no mercado fonográfico:

No final de 1990 foram lançados onze CDs Dose Dupla (com dois elepês cada) de Tião Carreiro e Pardinho, mais outros três da série Som da Terra, todos pela gravadora Chantecler/Warner Music Brasil. São remasterizações de elepés que, por sua vez, foram em boa parte ou regravações ou cópias de 78 rpm de sucesso. Dona Nair Avanço Dias, viúva de Tião Carreiro, relatou-me que "nunca o Tião vendeu tanto como agora. E não é porque ele morrev e dá sensação de perda, mas porque o povo está valorizando mais a moda caipira.' Desta constatação conclui-se: a Moda Caipira de raízes, com suas 'palavras estropiadas' e tão sertão, não sai de moda, não se exaure facilmente com o tempo, constituindo-se talvez, em seu conjunto, no maior fenômeno da mídia em discos, e com

$38 \bigcirc$ autor complementa que "Em grande medida, sob o modelo de Barretos[SP], nas últimas cinco décadas do século XX, 'rodeio' passou a designar mais claramente o lugar das competições, exibições e rituais equinos e bovinos e se tornou espetáculo mercantil massivo, produzido por empresas, promotores e profissionais especializados, que visam consumidores das cidades com vida urbana mais densa" (ALEM, 2004-2005, p. 99). 
mais longevidade, na fortuna chamada Música Popular Brasileira. É raríssimo no Brasil um artista que, vivo ou ido, brasileiro ou estrangeiro, tenha lançado catorze CDs, no período de vinte e quatro meses, como é o caso do fenômeno Tião Carreiro e Pardinho (SANT'ANNA, 2000, p.94).

Além de Tião Carreiro, várias foram as duplas sertanejas de raiz que nesta época tiveram seus antigos LPs relançados em CDs Dose Dupla pela Warner Music Brasil ou em coletâneas de outras gravadoras.

Desta forma, no contexto da música sertaneja romântica massificada pós anos noventa, a predominância de elementos e matrizes caipiras em sua discografia fez com que Tião Carreiro definitivamente fosse reconhecido no mercado fonográfico como um artista do segmento sertanejo de raiz, mesmo que seus últimos discos incluíssem algumas inovações estilísticas. Seus LPs passaram, portanto, a ser identificados como reservas de matrizes caipiras, mesmo que já transformadas, para as novas gerações de violeiros e músicos que até os dias atuais redescobrem suas gravações.

Ao mesmo tempo, é interessante notar que boa parte das duplas e cantores do segmento sertanejo romântico e posteriormente do sertanejo universitário, passaram a registrar em seus CDs pelo menos uma releitura do chamado repertório de raiz, muitas vezes com arranjos tidos como "modernos". "Provavelmente isso representa uma estratégia de legitimação do disco e visa garantir identidade da produção com um público mais amplo" (ZAN, 2004, p.6). Como exemplo bem claro desta tendência, temos a série de CDs do cantor sertanejo romântico Daniel intitulados Meu Reino Encantado, Meu Reino Encantado II e Meu Reino Encantado III, lançados respectivamente em 2000, 2003 e 2005 também pela gravadora Warner, e que são coletâneas de clássicos do repertório de raiz registrados pelo cantor, incluindo a participação de intérpretes de duplas tradicionais como Irmãs Galvão, Tinoco e o próprio Pardinho. $O$ segundo CD desta série é uma homenagem justamente a Tião Carreiro, contendo apenas composições suas ou músicas que foram interpretadas pelo violeiro. 


\section{Referências}

ALEM, João Marcos. Rodeios: a fabricação de uma identidade caipirasertanejo-country. Revista USP, São Paulo, n.64, p.94-121, dezembro/ fevereiro 2004-2005.

AMARAL PINTO, João Paulo do. A Viola Caipira de Tião Carreiro. Dissertação (Mestrado) apresentada ao Programa de Pós-Craduação em Música do Instituto de Artes da Universidade Estadual de Campinas, Campinas-SP, 2008.

As características do pagode caipira de Tião Carreiro. Revista de Cultura Artística, v. 3, p. 31-43, 2010.

CALDAS, Waldenyr. Acorde na aurora: música sertaneja e indústria cultural. São Paulo: Editora Nacional, 1979.

CORREEA, Roberto N. Viola Caipira. 2 ed. Brasilia: Editora Viola Corrêa, 1989.

Corrêa, 2000.

A arte de pontear a viola. Brasilia, Curitiba: Editora Viola

DIAS, Márcia Tosta. Os donos da voz: indústria fonográfica brasileira e mundialização da cultura. São Paulo: Boitempo Editorial, 2000.

FABBRI, Franco. A theory of musical genres: two applications. In: HORN, David e TACG, Philip (Ed.) Popular Music Perspectives 1981, Göteborg and Exeter: International Association for the Study of Popular Music, p. 52-81). r, delivered at the First International Conference on Popular Music Studies (Amsterdam, 1980).

FERRETE, J.L. Capitão Furtado: viola caipira ou sertaneja? Rio de Janeiro: MINC/FUNARTE, 1985.

FREIRE, Paulo de Oliveira. Eu nasci naquela serra. A história de Angelino de Oliveira, Raul Torres e Serrinha. São Paulo: Editora Paulicéia. 1996.

CIFFONI, Maria Amália Correia. Danças miúdas do folclore paulista. $2^{a}$ ed. São Paulo: Nobel, 1980. 
IKEDA, Alberto T. Música da terra paulista: da viola caipira a guitarra elétrica. In: SETUBAL, Maria Alice(coord.). Manifestações artísticas e celebrações populares no Estado de São Paulo/ Centro de Estudos e Pesquisas em Educação, Cultura e Ação Comunitária, São Paulo: CENPEC, Imprensa Oficial do Estado de São Paulo, 2004. (Coleção Terra Paulista: histórias, arte e costumes; V.3). p. 141-167.

; PELLECRINI FILHO, Américo. Celebrações populares paulistas: do sagrado ao profano. In: SETUBAL, Maria Alice (coord.). Manifestações artísticas e celebrações populares no Estado de São Paulo/ Centro de Estudos e Pesquisas em Educação, Cultura e Ação Comunitária, São Paulo: CENPEC, Imprensa Oficial do Estado de São Paulo, 2004. (Coleção Terra Paulista: histórias, arte e costumes; V.3). p. 169-223.

KOSHIBA, Camila Gonçalves. CONÇALVES. Música em 78 rotações: "discos a todos os preços" na São Paulo dos anos 30. Dissertação de Mestrado apresentada ao Programa de Pós-Graduação em História Social do Departamento de História da Faculdade de Filosofia, Letras e Ciências Humanas da Universidade de São Paulo, São Paulo, 2006.

MARTINS, José de Souza. Capitalismo e tradicionalismo: estudos sobre as contradições da sociedade agrária no Brasil. São Paulo: Pioneira, 1975.

MUGNAINI, Ayrton Mugnaini Jr. Texto do encarte do CD Zé do Rancho (Violas), Série Luar do Sertão da gravadora BMC, lançado em 1997.

MULLER, Daniel Gustavo Mingotti. Música instrumental e indústria fonográfica no Brasil: a experiência do selo Som da Cente. 2005. Dissertação (Mestrado) apresentada ao Programa de Pós-Craduação em Música do Instituto de Artes da Universidade Estadual de Campinas, Campinas-SP, 2005.

NEPOMUCENO, Rosa. Música caipira: da roça ao rodeio. São Paulo: Editora 34, 1999.

PASCALL, Robert. In: Sadie, Stanley; Tyrrel, John (Eds). The New Grove: Dictionary of Music and Musicians ${ }^{\text {TM }}$. 2. ed. London: Macmillan, 200 I. v. 9, p.638-642. 
PASCHOAL, Guto. Sua Majestade a Viola: Rainha do Sertão. Mímeo, 1999.

POLICENO, Mário. Os 70 anos do Pelé da viola. In: Folha da Região. Araçatuba (SP): 12/12/2004.

SAMSON, Jim. In: Sadie, Stanley; Tyrrel, John (Eds). The New Grove: Dictionary of Music and Musicians ${ }^{T M}$. 2. ed. London: Macmillan, 2001. v.24, p.638-642.

SANT'ANNA, Romildo. A moda é viola: ensaio do cantar caipira. São Paulo: Arte \& Ciência; Marilia, SP: Ed. UNIMAR, 2000.

SANTOS, Alcino; BARBALHO, Gracio; SEVERIANO, Jairo AZEVEDO, M. A. Discografia Brasileira 78rom (1902- 1964). 5 vol. Rio de Janeiro: FUNARTE, 1982. Disponível para consulta no site da Fundação Joaquim Nabuco <http://www.fundaj.gov.br>. Acesso 2007.

SOUZA, Andréa Carneiro de. Viola: do sertão para as salas de concerto: a visão de quatro violeiros. Dissertação (Mestrado em Música) - Universidade do Rio de Janeiro. Rio de Janeiro, 2002.

(org). 2005. Viola Instrumental Brasileira. Rio de Janeiro: Artiviva Editora.

TINHORÃO, José Ramos. Historia Social da Música Popular Brasileira. Lisboa, Editorial Caminho. 1990.

1997.

As Origens da Canção Urbana. Lisboa, Editorial Caminho.

Surpresa é o som da viola de Tião Carreiro. In: Jornal do Brasil, Rio de Janeiro: 21/07/1976.

TONICO; TINOCO. Tonico e Tinoco: Da beira da tuia ao teatro municipal. São Paulo: Ática, 1984.

ULHÔA, Martha Tupinambá de; ARACÃO, Paulo; TROTTA, Felipe. Música Hibrida - Matrizes Culturais e a Interpretação da Música Brasileira. Comunicação do XIII Encontro Nacional de Pesquisa e Pós-Craduação em Música, 2003. 
ULHÔA, Martha Tupinambá de. A análise da Música Brasileira Popular. Cadernos do Colóquio. pp. 61-68. Publicação do Programa de PósGraduação em Música do Centro de Letras e Artes da UNIRIO, 1998.

VICENTE, Eduardo. Música e Disco no Brasil: A trajetoria da indústria fonográfica nas décadas de 80 e 90. Dissertação (Doutorado em Comunicações) - Escola de Comunicação e Artes, Universidade de São Paulo, São Paulo, novembro de 2001.

VILELA PINTO, Ivan. Na toada da viola. Revista USP, São Paulo, n.64, p.76-85, dezembro/fevereiro 2004-2005.

ZAN, José Roberto. Da Roça a Nashville: estudo sobre a nova música sertaneja. In Rua, Revista do Laboratório de Estudos Urbanos - LABEURB, $n^{\circ}$ I, Editora do Núcleo de Desenvolvimento da Criatividade - NUDECRI, UNICAMP, 1995.

Viola Nova. In: II Encontro Nacional da ABET (Associação Brasileira de Ełnomusicologia). Anais... Salvador, novembro de 2004.

Do exodo rural a indústria cultural. Jornal da Unicamp, $n^{10219}$ Campinas, julho de 2003.

\section{Outras Publicações}

Tião Carreiro na intimidade. In: Revista Moda e Viola, Ano I, nº 5, p. 37. Ed. Motivo Editorial 1990.

“Caipiras com Marketing”. Aramis Millarch. Estado do Paraná 14/05/1977.

"Tião Carreiro - É Ouvir e se Converter". Revista Moda e Viola, Ano II, $n^{\circ}$ 14, pag 10,11. Ed. Motivo Editorial 1991.

Revista Viola Caipira. Números 1, 2, 3, 4, 5, 6, 7, 8 e 9. Belo Horizonte: Editora São Gonçalo, 2003 a 2005.

Revista Modinhas Sertanejas nº 1, 2, 3 e 4. Editora Prelúdio, São Paulo, sem data.

Revista Melodias Sertanejas nº 1. Editora Prelúdio, São Paulo, sem data. 
Revista Tião Carreiro e Pardinho n ${ }^{10} 6$ - A História dos Reis do Pagode. Editora Prelúdio, São Paulo, ano provável 1973.

Revista Sertaneja - A Revista do Rádio e Disco Sertanejo, Ano I, nº 8, Novembro de 1958. Editora Prelúdio Limitada, São Paulo, 1958.

\section{Sites consultados}

ALBIN, Ricardo Cravo. Dicionário Cravo Albin da Música Popular Brasileira. Rio de Janeiro: 2002. Disponível em <http://www.dicionariompb. com.br>. Acessado de 2005 a 2007.

Acervo digital do Instituto Moreira Salles, disponivel em <http://www.ims. com.br>. Acessado de 2004 a 2007.

Banco de dados do Instituto Memória Musical Brasileira, disponível no site <http://www.memoriamusical.com.br>. Acessado em dezembro 2007.

Fundação Joaquim Nabuco, disponível em <http://www.fundaj.gov.br>. Acessado em 2007.

Site Oficial de Tião Carreio. Disponivel no endereço <http://www. tiaocarreiro.com.br> Acessado de 2005 a 2007.

"Viola Tropeira", disponível no endereço <http://www.violatropeira.com. br>. Acessado em 2007.

\section{Entrevistas e informações}

Luiz Faria da Silva (1947) - entrevista no dia 15/10/2007 em São Paulo.

Mairiporã (Roque de Moraes, 1947) - entrevista no dia 5/1 1/2007 em São Paulo.

Alex Marli Dias (1956) - conversas e informações concedidas nos anos de 2006 a 2007. 


\section{Referências Audiovisuais}

NUNES, José Dias. Vídeo da Apresentação na Churrascaria Assis. Tião Carreiro e Pardinho. Ituiutaba(MG) em 26/05/1990, (aprox. 60min): mímeo.

Vídeo da Apresentação Tião Carreiro e Pardinho em Jarnaúba(CO) em 3 1/03/1990, (aprox. 60min): mímeo.

Vídeo Apresentações de Tião Carreiro e Pardinho em Brodósqui(SP) 07/1 1/1990 e Cidade do Prata (MC) s.d.(aprox. 120min): mímeo.

"Música em São Paulo - uma breve história da música caipira". DVD documentário produzido pela Guanabara Records com patrocínio da Comgás, com participação de pesquisadores e artistas como: Zica Bergami, Inezita Barroso, Tinoco, Irmãs Galvão, Ivan Vilela, Paulo Freire, Conversa Ribeira, José Ramos Tinhorão, Zuza Homem de Mello, dentre outros. São Paulo: Guanabara, 2006 (aprox. 60min).

PORTO, Ciro. Out/2003. Chora Viola. Documentário sobre a viola caipira com diversos artistas. Campinas: EPTV Campinas.

"Mosaicos": Tião Carreiro. Programa exibido em 19/10/2007. TV Cultura, São Paulo.

\section{Referências Discográficas}

Diversos registros em 78rpm do acervo digital do Instituto Moreira Salles, disponivel em <http://www.ims.com.br>. Acesso 2006 e 2007.

Trechos do LP Viola Brasileira (Chantecler, 1963) de Antônio Carlos Barbosa Lima tocados no programa "Violão com Fábio Zanon" sobre Theodoro Nogueira e José Vieira Brandão, exibido Rádio Cultura de São Paulo em 19 de Julho de 2006. Disponível para consulta no site <http://vcfz.blogspot.com>. Acessado em junho de 2007.

Diversos músicas, discos, CDs, coletâneas de duplas, compositores e violeiros como Raul Torres e Florêncio, Alvarenga e Ranchinho, João 
Pacífico, Tonico e Tinoco, Zé Carreiro e Carreirinho, Cascatinha e Inhana, Jacó e Jacozinho, Zé Pagão e Faustino, Serrinha e Caboclinho, Palmeira e Luizinho, Vieira e Vieirinha, Zico e Zeca, Liu e Léu, Zilo e Zalo, Pedro Bento e Zé da Estrada, Cacique e Pajé, João Mulato e Douradinho, Zé Mulato e Cassiano, Poly, Zé do Rancho, Bambico, Cedeão da Viola, Téo Azevedo, Pena Branca e Xavantinho, Sérgio Reis, Léo Canhoto e Robertinho, Milionário e José Rico, Renato Teixeira, Rolando Boldrin, Tião do Carro e Odilon, Heraldo do Monte, Quarteto Novo, Renato Andrade, Almir Sater, Tavinho Moura, Roberto Corrêa, Ivan Vilela, Paulo Freire, Fernando Deghi, Levi Ramiro, Helena Meireles, Zé Côco do Riachão, Oliveira e Olivaldo, Os Favoritos da Catira, dentre outros.

Cópias em CD de todos os discos de 78 rpm de Tião Carreiro e Carreirinho não relançados em LPs cedidos pelo colecionador Antônio Mortarelli (vide discografia em anexo para maiores detalhes): Continental disco $n^{10}$ 17.544; RCA Victor discos no 802016, 802.072, 802.108, 802016; RCA - CAMDEM disco $n^{\circ}$ CAM 1089.

Toda a discografia referente aos LPs gravados por Tião Carreiro e relançados em CD pela Warner do Brasil em 2000:

Tião Carreiro e Pardinho. 196 I/2000. LP relançado em CD. Rei do Gado. Continental / Warner Music Brasil. São Paulo, Brasil.

Tião Carreiro e Carreirinho. 1962/2000. LP relançado em CD. Meu Carro é Minha Viola. Continental / Warner Music Brasil. São Paulo, Brasil.

Tião Carreiro e Pardinho. 1963/2000. LP relançado em CD. Casinha da Serra. Continental / Warner Music Brasil. São Paulo, Brasil.

Tião Carreiro e Pardinho. 1964/2000. LP relançado em CD. Linha de Frente. Continental / Warner Music Brasil. São Paulo, Brasil.

Tião Carreiro e Pardinho. 1964/2000. LP relançado em CD. Repertório de Ouro. Chantecler / Warner Music Brasil. São Paulo, Brasil.

Tião Carreiro e Pardinho. 1965/2000. LP relançado em CD. Os Reis do Pagode. Continental / Warner Music Brasil. São Paulo, Brasil.

Tião Carreiro e Pardinho. 1966/2000. LP relançado em CD. Boi Soberano. Continental / Warner Music Brasil. São Paulo, Brasil. Tião Carreiro e Pardinho. 1967/2000. LP relançado em CD. 
Pagode na Praça. Continental / Warner Music Brasil. São Paulo, Brasil.

Tião Carreiro e Pardinho. 1967/2000. LP relançado em CD. Rancho dos Ipês. Continental / Warner Music Brasil. São Paulo, Brasil.

Tião Carreiro e Pardinho. 1968/2000. LP relançado em CD. Encantos da Natureza. Continental / Warner Music Brasil. São Paulo, Brasil.

Tião Carreiro e Pardinho. 1969/2000. LP relançado em CD. Em Tempo de Avanço. Continental / Warner Music Brasil. São Paulo, Brasil.

Tião Carreiro e Pardinho. 1970/2000. LP relançado em CD. Sertão em Festa. Continental / Warner Music Brasil. São Paulo, Brasil.

Tião Carreiro e Pardinho. 1970/2000. LP relançado em CD. Show. Continental / Warner Music Brasil. São Paulo, Brasil.

Tião Carreiro e Pardinho. 1970/2000. LP relançado em CD. A Força do Perdão. Continental / Warner Music Brasil. São Paulo, Brasil.

Tião Carreiro e Pardinho. 197//2000. LP relançado em CD. Abrindo Caminho. Continental / Warner Music Brasil. São Paulo, Brasil.

Tião Carreiro e Pardinho. 1972/2000. LP relançado em CD. Hoje eu Não Posso Ir. Continental / Warner Music Brasil. São Paulo, Brasil. Tião Carreiro e Pardinho. 1973/2000. LP relançado em CD. Viola Cabocla. Continental / Warner Music Brasil. São Paulo, Brasil.

Tião Carreiro e Pardinho. 1973/2000. LP relançado em CD. A Caminho do Sol. Continental / Warner Music Brasil. São Paulo, Brasil.

Tião Carreiro e Pardinho. 1974/2000. LP relançado em CD. Modas de Viola Classe A. Continental / Warner Music Brasil. São Paulo, Brasil.

Tião Carreiro e Pardinho. 197 4/2000. LP relançado em CD. Esquina da Saudade. Chantecler / Warner Music Brasil. São Paulo, Brasil. Tião Carreiro e Pardinho. 1975/2000. LP relançado em CD. Modas de Viola Classe A - vol. 2. Continental / Warner Music Brasil. São Paulo, Brasil.

Tião Carreiro e Pardinho. 1975/2000. LP relançado em CD. Duelo de Amor. Chantecler / Warner Music Brasil. São Paulo, Brasil.

Tião Carreiro. 1976/2000. LP relançado em CD. É Isto que o Povo Quer - Tião Carreiro em Solos de Viola Caipira . Continental / Warner Music Brasil. São Paulo, Brasil. 
Tião Carreiro e Pardinho. 1976/2000. LP relançado em CD. Rio de Pranto. Continental / Warner Music Brasil. São Paulo, Brasil.

Tião Carreiro e Pardinho. 1977/2000. LP relançado em CD. Rancho do Vale. Continental / Warner Music Brasil. São Paulo, Brasil.

Tião Carreiro e Pardinho. 1978/2000. LP relançado em CD. Terra Rocha. Continental / Warner Music Brasil. São Paulo, Brasil.

Tião Carreiro e Paraíso. 1978/2000. LP relançado em CD. Viola Divina. Continental / Warner Music Brasil. São Paulo, Brasil.

Tião Carreiro e Paraíso. 1979/2000. LP relançado em CD. Seleção de Ouro. Continental / Warner Music Brasil. São Paulo, Brasil.

Tião Carreiro e Pardinho. 1979/2000. LP relançado em CD. Golpe de Mestre. Continental / Warner Music Brasil. São Paulo, Brasil.

Tião Carreiro e Pardinho. 1979/2000. LP relançado em CD. Pagodes vol. 02. Continental / Warner Music Brasil. São Paulo, Brasil.

Tião Carreiro. 1979/2000. LP relançado em CD. Tião Carreiro em Solo de Viola Caipira. Continental / Warner Music Brasil. São Paulo, Brasil.

Tião Carreiro e Paraíso. 1980/2000. LP relançado em CD. Homem até Debaixo d'água. Chantecler / Warner Music Brasil. São Paulo, Brasil.

Tião Carreiro e Paraíso. 1981/2000. LP relançado em CD. Prato do Dia. Continental / Warner Music Brasil. São Paulo, Brasil.

Tião Carreiro e Pardinho. 198 1/2000. LP relançado em CD. Modas de Viola Classe A - vol 3. Continental / Warner Music Brasil. São Paulo, Brasil.

Tião Carreiro e Pardinho. 1982/2000. LP relançado em CD. Navalha na Carne. Continental / Warner Music Brasil. São Paulo, Brasil.

Tião Carreiro e Pardinho. 1983/2000. LP relançado em CD. No Som da Viola. Continental / Warner Music Brasil. São Paulo, Brasil. Tião Carreiro e Pardinho. 1984/2000. LP relançado em CD. Modas de Viola Classe A - vol 4. Continental / Warner Music Brasil. São Paulo, Brasil.

Tião Carreiro e Pardinho. 1985/2000. LP relançado em CD. Felicidade. Continental / Warner Music Brasil. São Paulo, Brasil. Tião Carreiro e Pardinho. 1986/2000. LP relançado em CD. Estrela de Ouro. Continental / Warner Music Brasil. São Paulo, Brasil.

Tião Carreiro e Pardinho. 1988/2000. LP relançado em CD. A Majestade do Pagode Continental / Warner Music Brasil. São Paulo, Brasil. 
Tião Carreiro e Praiano. 1992/2000. LP relançado em CD. O Fogo e a Brasa - Tião Carreiro e Praiano. Continental / Warner Music Brasil. São Paulo, Brasil.

\section{Sobre o autor}

Seu contato com a música caipira originou-se quando, ainda criança, acompanhava seu pai nas cantorias em Mogi das Cruzes - SP, sua cidade natal, e nas pescarias de férias no sul Minas Gerais. Pósgraduado pela Unicamp, foi pioneiro ao defender o primeiro mestrado em música sobre a viola caipira do país, com pesquisa sobre o lendário violeiro Tião Carreiro. É professor de viola caipira da Faculdade Cantareira (desde 2009) e EMESP Tom Jobim (desde 2005), autor do método de viola utilizado no projeto Guri e do livro/CD "Viola Caipira arranjos instrumentais de músicas tradicionais", vencedor do prêmio Ney Mesquita. 